\title{
National RuRal Regional LaW and JUSTICE CONFERENCE
}

\section{Preface}

This special edition of the Deakin Law Review consists of selected papers presented to the inaugural National Rural Regional Law and Justice Conference, held in Warrnambool, Victoria, on 19-21 November 2010. The Conference provided a unique forum for people from a broad range of professions and interests to converge and share ideas, experiences and knowledge to advance equity and justice for rural and regional Australians. The Conference was attended by over 100 delegates from all states and territories, representing federal, state and local government, rural industry, legal practitioners, academics, Legal Aid, Community Legal Services, and indigenous, youth, and other regional advocacy and support services.

The Honourable Robert French, Chief Justice of the High Court of Australia, opened the Conference with an address that drew upon his early career experience as a practitioner in regional Western Australia. He provided an erudite and grounded perspective on rural law and justice issues. The Conference then heard three Keynote addresses and twenty-one papers that were presented across the three themes of Social Justice, Legal System Services and Legal Practice.

The Conference had ambitious aims: to 'influence and shape the direction of policy and debate in the provision of justice system services to regional Australia' and 'to highlight initiatives currently being undertaken in rural and regional Australia and focus attention on the areas of greatest need now and in the future'. While the achievement of these aims cannot easily be measured, undoubtedly the Conference has sown the seeds of change in a number of ways. Of particular note is the principle resolution of the Conference: to 'establish a National Rural Law and Justice Alliance', which is currently being developed under the guidance of a working group made up of Conference delegates. The formation meeting of the National Alliance is to be part of the second National Conference being organised by the University of 
New England in partnership with Deakin University - to be held in Coffs Harbour, NSW, in May 2012.

In addition, the establishment of a Deakin-based Centre for Rural Regional Law and Justice has, to a large degree, been driven by the findings of a research paper entitled Postcode Justice: Rural and Regional Disadvantage in the Administration of the Law which was delivered to the National Conference. ${ }^{1}$ Funded by the Faculty of Business and Law at Deakin University and a grant from the Victoria Law Foundation, the Centre for Rural Regional Law and Justice will pursue research and policy/law reform activities in the area of rural and regional law and justice.

The Conference papers selected for this special issue of the Deakin Law Review illustrate the diversity of law and justice issues which impact on rural and regional communities. The insights and innovations detailed within the papers alert us to the uniqueness of 'rurality' and the importance of taking it into account when we consider the equal provision of justice for all Australians. I am most grateful to the Editors and Board of the Deakin Law Review for the opportunity to have the important issues contained within these papers published to a wider audience and I thank the authors for their valuable contributions to the creation of knowledge and to the building of a dialogue in this diverse and burgeoning area of law and justice.

Richard Coverdale

Conference Co-ordinator

First National Rural Regional Law and Justice Conference

\footnotetext{
${ }^{1}$ Reproduced in this journal: (2011) 16(1) Deakin Law Review 155.
} 